\title{
Developing and introducing a post birth care plan (PBCP): an action research project.
}

CROWTHER, S., LAU, A. and MACIVER, E. 


\section{Journal Pre-proof}

Developing and introducing a post birth care plan (PBCP): An action research project

Susan Crowther PhD, MSc, BSc (Hons.), RM , Annie Lau PhD, MNS, BSc(Social Science/Nursing), RM , Emma Maclver PhD, BA (Hons), DipSW, PgCert HELT

PII:

DOI:

Reference:

To appear in:

Received date: Revised date: Accepted date:

$$
\text { S0266-6138(19)30307-9 }
$$

https://doi.org/10.1016/j.midw.2019.102616

$$
\text { YMIDW } 102616
$$

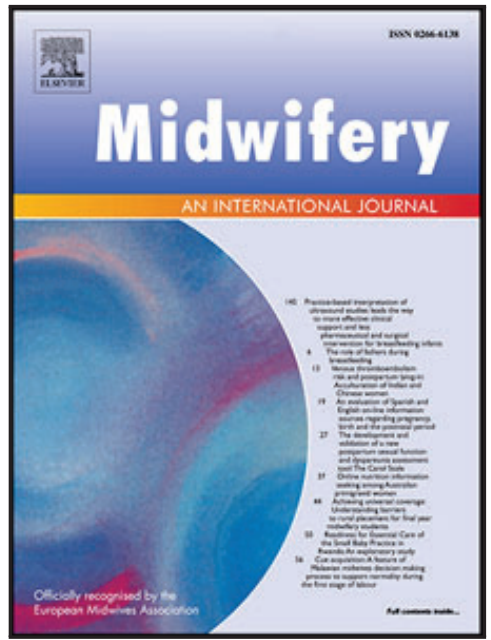

Please cite this article as: Susan Crowther PhD, MSc, BSc (Hons.), RM, Annie Lau PhD, MNS, BSc(Social Science/Nursing), RM, Emma Maclver PhD, BA (Hons), DipSW, PgCert HELT Developing and introducing a post birth care plan (PBCP): An action research project, Midwifery (2019), doi: https://doi.org/10.1016/j.midw.2019.102616

This is a PDF file of an article that has undergone enhancements after acceptance, such as the addition of a cover page and metadata, and formatting for readability, but it is not yet the definitive version of record. This version will undergo additional copyediting, typesetting and review before it is published in its final form, but we are providing this version to give early visibility of the article. Please note that, during the production process, errors may be discovered which could affect the content, and all legal disclaimers that apply to the journal pertain.

(C) 2019 Published by Elsevier Ltd. 
Title:

Developing and introducing a post birth care plan (PBCP): An action research project.

\section{Authors and affiliations:}

Susan Crowther: PhD, MSc, BSc (Hons.), RM. Professor of Midwifery, AUT University, Auckland, New Zealand. Twitter handle: @SusanCrowtherMW

Annie Lau* : PhD, MNS, BSc(Social Science/Nursing), RM. PgCert HELT, Midwifery lecturer, School of Nursing and Midwifery, Robert Gordon University, Aberdeen, AB10 7AQ, United Kingdom.

Emma MacIver, PhD, BA (Hons), DipSW, PgCert HELT, Research Fellow, School of Nursing and Midwifery, Robert Gordon University, Aberdeen, AB10 7AQ, United Kingdom. Corresponding author : Annie Lau, Midwifery lecturer, School of Nursing and Midwifery, Robert Gordon University, Garthdee Road, Aberdeen, AB10 7AQ, United Kingdom. Email: a.lau2@rgu.ac.uk

(1) Conflict of Interest - None declared

(2) Ethical Approval - Ethics approval for the study was granted by the NHS research Ethics Committee (reference 18/LO/1178) and the School of Nursing and Midwifery Ethics Review panel at Robert Gordon University (SERP reference number : 18-16).

(3) Funding Sources - The study was funded by a grant to SC and AL from the NHS Grampian Endowment funding to enhance maternity service in post birth care to women. The funding provided time and resources for the study. 
(4) Acknowledgments - The authors would like to thank all the women and community midwives who participated in the study and NHS Grampian Endowment (17/023) for funding the project and to the NHS Grampian managers for their facilitation of recruitment. 


\section{Introduction}

The concept of 'postnatal' is open to interpretation both in terminology and meaning and referred to in several ways such as 'post-birth' and 'postpartum' and in some contexts refers to '...the period from childbirth to the $42^{\text {nd }}$ day following delivery...' (World Health Organization, 2014), and elsewhere extending to 8 weeks post-birth. Generally greater emphasis is placed on pregnancy and less on women's postnatal individual needs and wishes (Kleppel et al., 2016). Post-birth care continues to receive the least focus (Declercq et al., 2013; Zadoroznyi et al., 2015). Nevertheless, this period is crucial in terms of supporting the physical and psycho-social wellbeing of the woman and newborn, including the establishment of breastfeeding, infant feeding support, bonding and attachment and transition to parenthood. Additionally, the postnatal period offers an opportunity to identify and monitor potential deteriorating health post-birth, including postnatal depression and psychosis, as well as social risk factors that may increase women and their family's vulnerabilities (Bick and Hunter, 2017).

The lack of post-birth focus is reflected globally in reports of dissatisfaction in meeting women's needs and expectations during post-birth care (Bick and MacArthur, 1995; Audit Commission, 1997; Marchant and Garcia, 2000; Royal College of Midwives (RCM), 2000; Brown et al., 2005; Cattrell et al., 2005; Waldenström et al., 2006; Newburn and Bhavnani, 2010; RCM, 2014; Zadoroznyj et al., 2015; Care Quality Commission, 2018; Rogers, 2018), demonstrating a need to improve the planning and delivery of effective person-centred postbirth care. For example, surveys of post-birth care in Scotland and across the United Kingdom (UK) (RCM, 2014, Scottish Government, 2015) have shown that post-birth care rarely lives up to women's expectations. Whilst regional differences were noted, data from across Scottish health boards revealed that $40 \%$ of women only sporadically receive the 
information or explanations that they need while they were in hospital post-birth. Similar findings are evident in relation to an English context, with $34 \%$ of women indicating that information received was insufficient to meet needs (Care Quality Commission, 2018). The UK national reviews of maternity services (Scottish Government 2017, NHS 2016) has consistently found that communication with healthcare professionals is essential to positive post-birth experiences and have called for improvements in this area.

Although development of a post-birth care plan (PBCP) with women in the antenatal period is part of national guidance (NICE, 2015), evidence demonstrates this is rarely performed (RCM, 2014). Women continue to report unmet needs for information, guidance and support on a range of post-birth concerns including self-care (Zadoroznyj et al., 2015; Declercq et al., 2013); postnatal maternal ill health, baby-care, support with breastfeeding (Zadoroznyj et al., 2015; Rudman and Waldenström., 2007) and an opportunity for a birth debrief (Zadoroznyj et al., 2015). A Royal College of Midwives (RCM) (2014) UK wide postnatal survey highlighted that only $25 \%$ of midwives used women's needs to plan post-birth care. The majority of midwives reported pressures of service needs dictating the post-birth care delivered to women. This is often related to the current fragmentary approach to post-birth care in which several different professionals provide care leading to complaints about poor communication and lack of individualised information (Kleppel et al., 2016).

Lack of information consistency is further compounded when women come from diverse ethnic backgrounds who present with increasingly more medical and psychosocial complexities (National Health Service Information Services Division, 2016), leading to potential for higher rates of morbidity and mortality (Scottish Government, 2017). Freedman and Lucas (2015) in their interpretation of the 'Mothers and Babies: Reducing Risk through Audits and Confidential Enquiries across the UK' (MBRRACE-UK) 2009 -2012 report found 
a minimal reduction in mortality rates and concluded that robust planning throughout the continuum of childbirth needs to occur to improve health outcomes and improve satisfaction with services. Post-birth care is part of the childbirth continuum and maternity experience and yet is often regarded as less important than antenatal and intrapartum care despite being part of the overall provision of services.

The aim of this study was to explore midwives and women's experiences, views and perspectives of post-birth care planning and develop an effective resource for women and midwives to use when planning post-birth care. Initially the study team completed a scoping review of the literature on post-birth care planning to understand what is already known and what (if any) similar projects had been undertaken (Authors 1,3,2, 2019). The review identified that post-birth care planning is promoted extensively in health policy and there is emergent evidence for its implementation. Yet there is a lack of practice examples and only one evaluation on PBCP (North West London STP, 2018). Despite an extensive literature search, including countries with an established maternity infrastructure, no evidence or examples of further PBCP were found, other than from those used by doulas (an example can be accessed via sarahtessier.com). Subsequently, an action research methodology was used to create a PBCP template that could be used in practice to guide conversations that could enhance women's post-birth experiences. The final 'product' of this study is not a detailed care plan standardised for all women but a series of questions and areas to explore personalised post-birth care needs for individual women.

\section{Methods}

Action research was chosen because it is an approach which identifies problems, is context specific and future orientated and interlinks planning, action and evaluation (Waterman et al., 2001). Action research is undertaken expressly with and for its participants offering the 
opportunity to work with people in a non-hierarchical and non-exploitive way (Hart \& Bond, 1995). The methodology is educative, works with individuals as members of social groups and as such is focused on change and improvement in current practice. Action research involves a cyclic process in which research, action and evaluation are interlinked - this study was conducted over three stages. Stage one was the scoping review published elsewhere (Authors 1,3,2, 2019).

\section{Stage 2: Recruitment of participants and gathering the data}

This study was undertaken in one NHS region in Scotland (XXX). Community midwives and women registered to one of two community midwifery teams in XXX were recruited. These teams were identified by the Chief Midwife for XXX. The midwives had a dual role: recruitment of women participants and as study participants themselves.

Figure 1: Stages 2 \& 3 - Recruitment, Data-Gathering, Analysis and Development of PBCP

STAGE 2

STAGE 3

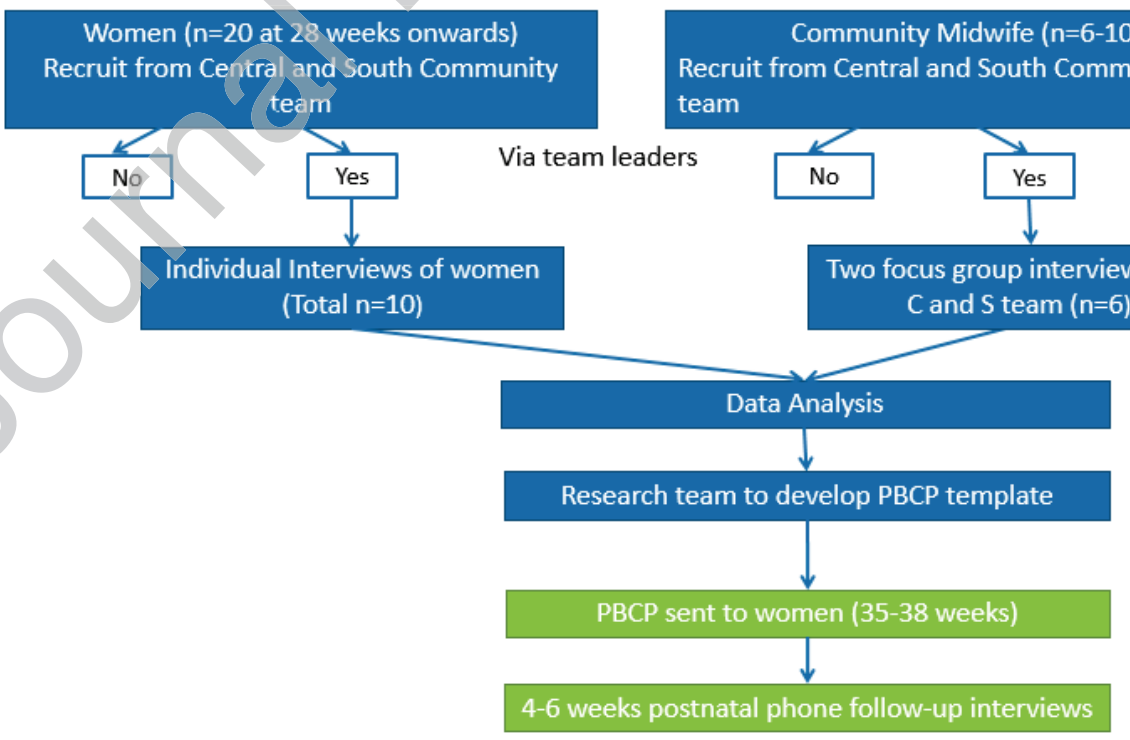




\section{Recruitment and Interviewing of Women}

The voices of pregnant women were of central importance and therefore, recruiting suitable women for interview was critical. Access was facilitated through the team leaders of the two community midwifery teams. They were initially responsible for disseminating information about the study to the midwives in their team, who in turn, identified and approached suitable women about the research and gauged their interest in participation. Criteria for inclusion in the study comprised women over 16, who were between 34-36 weeks pregnant at the time of interview, with an ability to read and speak English fluently. Those excluded were women with known mental health concerns.

Women fitting these criteria were initially briefed about the research at their 28 -week antenatal appointment and provided with a letter from the Chief Midwife explaining the remit of the research, a participant information sheet (PIS) and a consent form. The two team leaders were then responsible for collating and passing on the details of potential participants (with the women's agreement) to the research assistant who thereafter, followed-up with telephone calls with the women and set-up interviews if appropriate.

A total of 10 women were recruited. Eight women chose to be interviewed at home and two women, at the University campus. All were informed that a partner could be present (both as a support person and as a contributor), but all chose to be interviewed alone.

\section{Recruitment of Midwives and Focus Group Interviews:}

Community midwives working within either of the two teams were invited to take part in a focus group to explore their professional views on PBCP. Community midwife teams in this region of Scotland provide antenatal care from booking and provide some intrapartum care for women choosing a home birth and share on call arrangements. They also provide 
postnatal care in the community up to day 10 and on occasions up to 28 days if there are ongoing concerns. Intrapartum care and hospital postnatal care is provided by hospital-based midwives. In this model women are not cared for by a named midwife throughout all their maternity experience, receiving care from two or more midwives during their pregnancy and post-birth periods. Furthermore, women with complications may have the majority of their antenatal care by different members of the maternity team in the hospital. The small community teams from which the participants are based share the philosophy of continuity of carer in principle, but in practice this was not fully possible to achieve, due to part-time working hours and wide geographical spread. Whilst continuity of carer was not achieved, the midwives were confident that women were provided with continuity of care due to excellent communication among small teams. Initially, the plan was to conduct one focus group involving 6-10 midwives, but the wide geographical spread of the areas covered by the teams meant that this was not possible. Therefore, two focus groups were conducted - one for each team, with three participants in each group. Prior to the focus groups, midwives were provided with a Participant Information Sheet (PIS), outlining their involvement and how the data would be used and managed.

Principles of good ethical practice in line with GDPR (Information Commission Office, 2018) were followed and reiterated to women and midwife participants prior to interview/focus groups. All participants agreed to be audio-recorded and consent forms were completed.

\section{Data Analysis for development of PBCP template}

All interviews were transcribed in full and thematic analysis of the data was undertaken, employing guidance from Braun and Clarke (2006). This involved an iterative process moving from individual interviews to all of the interviews together, going back and forth, 
until agreement was reached. All three members of the research team coded and analysed the data independently, discussed the emerging themes and developed the coding tree.

The PBCP template was informed by the themes generated in the data analysis and contrasted and compared to the findings of the scoping review. The template developed into a series of questions grouped into physical, social and holistic family needs which could be explored by midwife and woman (and partner if present) before birth. The content and style of the PBCP were agreed through collaboration and consensus by the research team, participants (women and midwives) and clinical managers.

\section{Stage 3: Distribution, trialling and reaching consensus on PBCP template}

The PBCP template was posted to participant women around 38 weeks of pregnancy and a copy sent to their named midwives. The women were contacted to ensure they had received and fully understood how to use the PBCP template and a provisional time for a follow-up telephone post-birth interview at 4-8 weeks agreed. The women and their partners were encouraged to use the PBCP as a conversational guide to discuss their post-birth care needs with their midwives at their next antenatal visit and following the birth of their babies. The completed PBCP were held by the women for ongoing conversations with their midwives.

\section{Telephone follow up}

Before any telephone follow-up was made, the research team ascertained the well-being of participant women with the community midwife leaders. Telephone follow-up interviews explored the women's views and experiences of using the PBCP, specifically whether their PBCP supported their post-birth care needs. Three key areas have previously been identified in terms of a) women's experience, b) information given and c) maternal care service 
evaluations (Scottish Government, 2017). Therefore, satisfaction with use of a PBCP was explored in the following ways:

a) having experienced PBCP, whether women's perceptions were of being treated with respect and dignity;

b) were women being given information or explanations they needed;

c) did women feel involved in decisions about their own and their baby's care.

The telephone interview data was analysed as in stage 2 and findings used to guide improvements in the template and provide recommendations for future work on post-birth care planning.

\section{Findings}

The demographic characteristics of the participants are outlined below - see Table 1 for the women participants and Table 2 for the midwives. 
Table 1: Demographic characteristics of the women

\begin{tabular}{|c|c|c|c|c|}
\hline $\begin{array}{c}\text { Participant } \\
\text { (All names are } \\
\text { pseudonyms) }\end{array}$ & Age & Ethnic origin & $\begin{array}{c}\text { Gestation } \\
\text { (weeks) }\end{array}$ & Parity \\
\hline 1. Linda & 27 & Scottish & 35 & Primiparous \\
\hline 2. Nicola & 31 & Scottish & 34 & Primiparous \\
\hline 3. Jennifer & 37 & Scottish & 33 & Multiparous \\
\hline 4. Emily & 32 & Scottish & 3 & Multiparous \\
\hline 5. Liz & 40 & Scottish & 33 & Multiparous \\
\hline 6. Ela & 29 & & 29 & Primiparous \\
\hline 7. Jill & 32 & Scottish & 31 & Multiparous \\
\hline 8. Caroline & 30 & Scottish & 31 & Primiparous \\
\hline 9. Katie & & Indian & 32 & Primiparous \\
\hline 10. Roma & 33 & Scottish & 32 & Primiparous \\
\hline
\end{tabular}


Table 2: Demographic characteristics of the community midwives

\begin{tabular}{|l|c|c|c|c|}
\hline $\begin{array}{l}\text { Midwife } \\
\text { participant } \\
\text { (All names are } \\
\text { pseudonyms) }\end{array}$ & Team & Age & $\begin{array}{c}\text { Years of practice } \\
\text { experience }\end{array}$ & Position \\
\hline 1. Tracy & Central & 52 & 29 & $\begin{array}{c}\text { Community } \\
\text { midwife }\end{array}$ \\
\hline 2. Erin & Central & 43 & 7 & $\begin{array}{c}\text { Community } \\
\text { midwife }\end{array}$ \\
\hline 3. Ester & Central & 32 & 2 & $\begin{array}{c}\text { Community } \\
\text { midwife }\end{array}$ \\
\hline 4. Amy & South & 57 & 33 & $\begin{array}{c}\text { Community } \\
\text { midwife }\end{array}$ \\
\hline 5. Lisa & South & 54 & 26 & $\begin{array}{c}\text { Community } \\
\text { midwife }\end{array}$ \\
\hline 6. Kyra & South & 50 & 26 & $\begin{array}{c}\text { Community } \\
\text { midwife }\end{array}$ \\
\hline
\end{tabular}

Themes were developed from analysis of women's interviews and the midwife focus groups.

Data analysis identified seven themes (see Table 3). The results combined to develop core elements of a working PBCP template. 
Table 3: Themes and subthemes from analysis of women individual data and focus groups of the midwives

\begin{tabular}{|c|c|}
\hline Themes & Sub-themes \\
\hline Being prepared for transitions & $\begin{array}{l}\text { Prepared for pregnancy but not beyond } \\
\text { Planning for the unknown particularly for first-time mothers } \\
\text { Setting realistic expectations (including sibling relationships) }\end{array}$ \\
\hline Physical needs & $\begin{array}{l}\text { Women's needs related to post-birth bodily functions } \\
\text { Needs of the newborn(s) }\end{array}$ \\
\hline Psycho-emotional needs & $\begin{array}{l}\text { Psycho-social well-being } \\
\text { Peer support } \\
\text { Professional/midwifery support } \\
\text { Father and family support } \\
\text { Self-help (from women's own knowledge and other resources) }\end{array}$ \\
\hline $\begin{array}{l}\text { Cultural, religious and spiritual } \\
\text { needs }\end{array}$ & Different cultural practice in post-birth period \\
\hline $\begin{array}{l}\text { Organisation of care } \\
\text { information }\end{array}$ & $\begin{array}{l}\text { Permission-giving and seeking } \\
\text { Relationships and continuity of care(r) } \\
\text { Professional roles of maternity care team (such as maternity } \\
\text { care support workers, health visitors, general practitioners, } \\
\text { paediatricians, student midwives) } \\
\text { Immediate post-birth logistics (such as hospital post-birth } \\
\text { environment, food, visitors, self-care) } \\
\text { Timing of discharge and post-birth home visiting schedule }\end{array}$ \\
\hline Knowledge transfer & $\begin{array}{l}\text { Timing, type, accessibility and consistency of knowledge } \\
\text { Expectations about information (for example pain relief and } \\
\text { post-birth discharge). }\end{array}$ \\
\hline $\begin{array}{l}\text { Financial information and } \\
\text { guidance }\end{array}$ & $\begin{array}{l}\text { Social security benefits, costs of equipment (such as nursery } \\
\text { equipment), cost associated with childcare on return to work }\end{array}$ \\
\hline
\end{tabular}




\section{Being prepared for transitions}

The theme reflected the common experiences of women and observations from the midwives, particularly regarding first-time mothers who tended to concentrate discussion around pregnancy, labour and birth. First-time mothers commented that it was difficult to consider post-birth care as it is an unknown experience and they did not know what to expect.

I'm a first-time mum, so I don't really know what I expect (Woman, Linda).

This appreciation of first-time mother's needs was reflected by midwives too,

[They] can read books, but the practicality is different (Midwife, Tracy).

But then the difference between a lady on day 1 and day 10 is huge, they

really do turn a big corner in that time ... it's just about building

confidence (Midwife, Erin).

\section{Physical needs}

Women participants commonly discussed their own and/or their newborn's physical needs. In terms of the women's own needs, this included immediate bodily functions after birth such as bleeding, wound care, sleeping, pain, breast care, mobility and diet as well as managing stairs and driving.

I didn't really know what was normal...Advice on how to care for stitches or tears or any other kind of healing. That medical side of things, at what point do you go to your GP or do you go back in to the hospital or if you start running a fever, do you call the ward, do you call your GP, do you call whatever it is, the NHS direct. That's not that clear (Woman, Jennifer).

Relating to the baby's physical needs, women raised queries around general hygiene, sleeping, bathing and bowel movements. They were also unsure about the newborn examination, screening and vaccinations and potential future health issues. 
I know that my midwife will be coming for approximately 10 days and they will be taking tests for baby and I don't know... as this is my first child and this is a precious baby for me, I will be very anxious (Woman, Katie).

As expressed by one woman, having a community midwife check and endorse their arrangements was reassuring:

And when you're talking about sleep and where the baby should sleep, it was nice actually, because you had a midwife visit your home. She didn't ask to have a look, but I wanted to show her where we'd got baby set-up and how that was working and she was like 'yeah that's fine that adheres to all the guidance no problem', which was reassuring... (Woman, Jennifer).

One woman expressed concern about genetic issues in her family potentially affecting her newborn baby:

We know baby's healthy, from scans and stuff, but my husband has Crohn's disease, it's always this 50/50 chance he could have it and we don't know when... My husband also had asthma when he was a kid, I have a grandmother with asthma, so it's a lot of stuff... You want a healthy baby, everybody does (Woman, Ela).

The most commonly discussed issue among both women and midwives related to infant feeding, in particular the dilemmas around breast and formula feeding.

The thing constantly on my brain, is about the feeding, I would love to breast feed if I can. It's not the biggest deal in the world if I can't, I'm not going to put that pressure on myself...(Woman, Caroline).

\section{Psycho-emotional needs}

Women referred to their emotional needs in the post-birth period. They talked about these in terms of what was normal and could be expected and what required attention or referral. 
I suppose just making sure that I'm well within myself, nobody's really mentioned postnatal depression and a few of my friends have felt low but nobody's really said just being an off day to well you've got postnatal depression It would be helpful to know what's to expect with your mood afterwards...it would be nice to know what your mental health is going to be like after you've had your baby (Woman, Linda).

In contrast, the midwives felt that they addressed postnatal depression and general mental health with women but could be more explicit about anxiety:

I think these women are getting much better at being open about mental health and the way they're feeling and their tiredness and their emotions... we talk a lot about the feelings and the hormones and in the antenatal period you're talking about that and you're also talking about the possibility of postnatal depression and that is one of the things we do well I would say. But the actual little anxieties that they might have in the postnatal period, I don't think we're good at bringing that up in the antenatal period (Midwife, Lisa).

\section{Cultural, religious and spiritual needs}

Several women discussed their cultural needs around post-birth highlighting a wish for a longer postnatal recuperation period, the significance of support from wider family networks and expectations of newborn care and follow-up postnatal care.

I don't know how long your mum stays with you, I don't know the culture here, but back home your mum stays with you for a long time, til the baby's 2 or 3 months and when you get the baby, they shower and clean the baby, but here, they just wipe the baby. It is different from what I expect. (Woman, Katie).

Similarly, the midwives discussed diverse postnatal cultural practices that they have observed. This included dilemmas such as overclothing the baby, leading to potential safety concerns around overheating. 
I went into a Pakistani family... and the granny was doing all these weird and wonderful things to the baby and she (mother) said, 'Can you please just tell her that we don't do that here'. I went in to a house, and they all slept in the one room. Downstairs, the house was roasting as the granny had come over from the heat and the baby was wrapped up in a big blanket, when I took the blanket off the baby it was soaking, her and her partner were very well educated and I said you need to turn the gas fire off and this blanket can't be used. I went to wash my hands and came back and the granny had the baby all wrapped up in the furry blanket again, so it's dangerous sometimes (Midwife, Lisa).

Midwives could appreciate the importance of exploring cultural needs in a PBCP and how it is important to provide individualised care:

Some of the Arabic ladies put coal over the baby's eyes. ...there's a lot of cultural things there, where one size doesn't fit all. So it would be interesting to incorporate some of that into a PBCP. It will be very difficult to make a PBCP I think, because there's no two houses the same. Because that is the way we look at birth and labour though, a one size fits all (Midwife, Kyra).

\section{Organization of care information}

There was much discussion among both women and midwives about how information on postnatal care is provided in terms of when, how and by whom. For instance, women appreciate continuity of carer so that consistent information could be provided by known and trusted midwives.

If I could choose, I'd have G (community midwife) for all my appointments, $G$ for my birth and $G$ for all my postnatal appointments. And if $G$ needs to go on holiday, I'd have L (other midwife in team). If you knew it was going to be one of a small pool, then that would be nicer than having whoever is on call from local maternity hospital (Woman, Jennifer). 
In terms of specific information, women wanted to know about the roles and remit of the professionals potentially involved in their care. They also wanted to know about the timing of discharge and home visiting schedule as well as immediate post-birth logistics including hospital post-birth environment, visitors, food and self-care.

I don't actually know how long I see the midwife for after I've had the baby. Obviously I'll see her, but it's only up to a certain amount of time and then the health visitor comes in ...it would be a nice chance to see the health visitor (HV) before (the birth), to come in and say this is your HV, maybe once you've had your baby I'm sure they'll mention that, but it's always nice to put a face to a name (Woman, Linda)

Conversely, the midwives emphasised that flexibility in the post-birth visiting schedule is important.

I don't make a long-term plan with them; I make a visit by visit plan. So rather than saying these are the visits I'd like to see you, I'd say this is my next plan of action, this is when I'd like to do this by, how do you feel about that, so it's planned as we go along (Midwife, Erin).

Interestingly, the women and midwives highlighted the notion of permission-giving and seeking. For the women, they expressed a need to obtain permission from the midwife in order to affirm their choice about self-care and baby care.

I'll just be guided by the nurses to be honest, they're the professionals, they know what's right and what's wrong. In terms of a plan afterwards, I haven't really considered it, I'll just do what I'm told. They know best (Woman, Roma).

Paradoxically, the midwives commented that women prefer being told what to do and sought approval from their midwives around post-birth care. 
We're getting to the point as a society, we spoon feed these women such a lot, that the information that we do give them, when it comes to the point they have to stop and think about it themselves, they kind of get a bit lost. I need someone to tell me what to do. Different for women that have had babies before, but with first babies... Oh I need someone to tell me this is okay, this is normal, that I'm allowed to do this (Midwife, Kyra).

\section{Knowledge transfer}

This theme refers to the timing, type, accessibility and consistency of knowledge. Women generally found information offered by peers, as well as NHS web-based materials most useful, albeit the latter depended on the guidance being up-to-date and reliable. Both women and midwives had mixed views about the online maternity tool, XYX (an electronic record of all aspects of maternity care), adopted by XXX and its associated application. Some found it a useful tool to remind them of upcoming appointments with midwives and for accessing prenatal test results. There were some concerns, however, that the tool could be more userfriendly, and that relevant information within it should be more accessible.

I hardly log in to it [XYX], it's just for your appointments is it...and doing your booking in, it's got all the questions they ask you and every time you go, you get your blood pressure and...like blood tests, I think there's a bit you can fill in, like a birth plan, but I've not got there. I don't (use it), I don't know what else it has on it (Woman, Emily).

In general, participants felt information provided by their midwives was useful.

But I know my midwife is there if I have any questions and you can ask them the next time you're in for an appointment or phone them up, but I don't want to seem like I'm bothering them all the time. They gave me a booklet on breastfeeding as well, so that's always handy to have, for quick reference (Woman, Emily). 
A few women emphasized that the information given by their families was contradictory and outdated.

I'm kind of at the age now where a lot of my friends are having babies or have had fairly recently, so I'm quite fortunate. Obviously family as well, they've all been there. But obviously times have changed significantly. Methods of doing things are recommended differently as well (Woman, Roma).

As well as a need to access up-to-date information, women expressed their wish for this to be provided at the right time and readily accessible and consistent. However, midwives were concerned about how and when information is delivered to women and if such information is actually retained.

How do we get them to retain that information once they've got that baby in their arms, that they remember that kind of things, they seem to remember the labour side of things, but no matter what you tell them in the antenatal classes, they don't retain that information (Midwife, Lisa).

\section{Financial information and guidance}

Initially this theme was developed because in the early interviews with women, the issue around returning to work and buying nursery equipment were discussed. Interestingly, none of the women or midwives raised financial concerns as relating to themselves or their clients (such as reduced income, additional costs or welfare benefits). This might reflect the socioeconomic geographical profile of the study participants.

There must be mothers out there in quite dire circumstances having babies, struggling to financially afford the next one and that's on their mind (Woman, Liz).

\section{The PBCP template}


Based on the findings of the scoping review and data analysis an initial PBCP template was developed. The key features of the template consist of five key domains capturing understanding maternity services and women's preferences: immediate post-birth care (including physical, social and emotional care); my health and wellbeing after birth; my baby's health and wellbeing; and transitions, adaptations and relationships.

\section{Stage 3: Telephone follow up with women and midwives}

Nine women responded to the telephone follow-up. The participants reported that the PBCP facilitated post-birth planning, especially for first time mothers who did not know what to expect. Post-birth care needs were not limited to postpartum physical care and infant care but needs around psychosocial self-help, sources of support and available resources. Overall the PBCP template was viewed as very useful as it provided cues to meaningful conversations together with the midwives. The exploration and cultural aspects on health and wellbeing after birth were valued by women and promoted feelings of inclusivity. The section on infant feeding was found to be useful because it did not focus exclusively on breastfeeding and included formula and mixed feeding. Seven women commented that the PBCP was rather lengthy whilst two women commented that the $\mathrm{PBCP}$ was proportionate in relation to the areas that required to be addressed. The feedback from midwives suggested that the PBCP was acceptable and useful in principle, but they were concerned about additional time pressures. The actual content and style of the template required no alterations on completion of stage 3 (see supplementary material 1: Final PBCP template).

\section{Discussion}

For women, post-birth care planning together with midwives in the antenatal period is an important aspect of post-birth care that is often neglected or hidden within institutional needs that do not favour relational care. This study has established a need and desire for some form 
of PBCP by both women and midwives caring for them and illustrates the significance of personalised relational care with, when possible and achievable, a known carer. There is evidence to support such a model of care in terms of safety, preference and satisfaction (Sandall et al., 2016). Haggerty et al. (2003) described continuity as having three elements: informational, management, and relational. This description distinguishes continuity from more fragmentary models of healthcare. We know that midwifery continuity facilitates lower rates of interventions, higher rates of physiological births, more maternal satisfaction and positive practice experiences for midwives when all these elements are in place (Homer et al., 2019). What this study has shown is how individualised care is better facilitated when there is improved informational continuity and that this would be improved with managerial and relational continuity. However managerial and relational continuity is not always feasible or practicable due to organisational structures and use of local resources and this is where a PBCP would support women by addressing the informational element of continuity. The women and midwives in this study illustrated how a PBCP can be used to establish meaningful conversations between women/families and their midwife using an open questioning format which encourages a conversational style of care. Using a PBCP provides an opportunity for women to explore their post-birth needs together with their midwife whilst knowing that other midwives, who they may meet on their journey through to the post-birth period, will know their preferences for care and needs around specific information. What remains to be understood is whether a PBCP should be a standalone tool or a tool embedded within the pregnancy and birth planning as part of the whole childbirth journey.

Further work needs to be done concerning midwives' workloads, timing and models of care in delivering this PBCP. This is necessary given the challenging staffing issues and low staff morale among midwives (RCM, 2016), as well as the increasing cultural diversity, health complexity and dominant risk discourse meeting midwives daily in practice (Coxon et al., 
2019). Conversely, it could be argued that the introduction of a PBCP, as described here, could mitigate some of the concerns around time, lack of continuity and the myriad cultural, social preferences and psychological, emotional and medical needs midwives are confronted with daily in practice. The study highlights how women defer to the perceived wisdom of the professional and the organisation of care. A PBCP could lessen the power relations existing in maternity systems and help mitigate much of the current system wide impersonal manner in which women's preferences and compassionate care are often superseded by the needs of institutional practices (Author 1 et al, 2019). The results of this study show how persistent fragmented models of care are disempowering and maintain an attitude in which women feel a need to seek 'permission' from midwives who are representing and working to the standard rules and practices of the institution.

It is known that women prefer relationships with care providers based on trust built over time (Lewis et al., 2017). Implementation of evidence-based continuity of carer for all women, regardless of risk status, would facilitate person-centred care and empower women.

Unfortunately, continuity of midwifery care for all women is yet to be realised and sustained across all regions (Homer et al., 2019). What is certain is that any tool or/and process that enables women's empowerment is useful; implementation of a PBCP could be one such intervention to lessen the negative effects of fragmentary maternity systems by explicitly supporting personalised care and improving informational continuity.

\section{Strengths and limitations}

Whilst hosting two separate midwife focus groups limited the opportunity for cross-team discussion, it proved to be the only feasible and practicable solution and indeed, the resulting data gathered offered a rich insight into the professional views and experiences of these midwives. Equally whilst interviewing more women from a more diverse social-economic 
background would have provided more nuanced social related findings the template has endeavoured to be broad in scope whilst individually focussed with the questions that were developed. Although the study is small and therefore not generalisable to all other regions it provides a transferable template in similar resourced regions that can be further trialled and developed.

\section{Implications for practice}

PBCPs provide an opportunity for women to explore their post-birth needs and have meaningful, respectful conversations with their midwives during the antenatal and post-birth period, potentially increasing their satisfaction with services. This study needs to be taken in the context of under-resourced postnatal care in current maternity services.

\section{Future research}

Full-service evaluation is required of the template before further implementation. Any upscaling needs to be workable and sustainable in practice, taking account of fiscally constrained services. In addition, introduction of PBCP along with continuity of care models warrants further research to ascertain the benefits in terms of wellbeing outcomes and maternal satisfaction.

Acknowledgments - The authors would like to thank all the women and community midwives who participated in the study and NHS Grampian Endowment (17/023) for funding the project and to the NHS Grampian managers for their facilitation of recruitment 


\section{References}

Audit Commission for local authorities and the National Health Service in England and Wales, 1997. First class delivery. Improving maternity services in England and Wales. London: Audit Commission, pp.176-184.

Bick, D. and Macarthur, C., 1995. The extent, severity and effect of health problems after childbirth. British Journal of Midwifery, 3(1), 27-31.

Bick, D. and Hunter, C., 2017. Content and organization of postnatal care. In: S MacDonald., and G. Johnson. (Eds.), Mayes Midwifery. Elsevier, London, pp. 694-704.

Braun, V., \& Clarke, V., 2006. Using thematic analysis in psychology. Qualitative research in psychology, 13(2), 77-101.

Brown, S., Davey, M. and Bruinsma, F., 2005. Women's views and experiences of postnatal hospital care in the Victorian Survey of Recent Mothers 2000. Midwifery, 21(2), 109-26.

Care Quality Commission, 2018. Survey of women's experiences of maternity care. Care Quality Commission: UK.

Cattrell, R., Lavender, T., Wallymahmed, A., Kingdon, C. and Riley, J., 2005. Postnatal care: what matters to midwives. British Journal of Midwifery, 13(4), 206-213.

Coxon, K., Scamell, M., \& Alaszewski, A., 2019. Risk, Pregnancy and Childbirth. Taylor \& Francis, London.

Authors 1,3,2, 2019.

Author 1 et al, 2019.

Declercq, E., Sakala, C., Corry, M., Applebaum, S. and Herrlich, A., 2013. Listening to Mothers III: Pregnancy and Birth. Childbirth Connection, New York.

Freedman, R., \& Lucas, D., 2015. MBRRACE-UK: Saving Lives, Improving Mothers' Care - Implications for anaesthetists. International Journal of Obstetric Anesthesia, 24(2), 161 173.

Haggerty, J. L., Reid, R. J., Freeman, G. K., Starfield, B. H., Adair, C. E., \& McKendry, R. (2003). Continuity of care: a multidisciplinary review. British Medical Journal, 327(7425), 1219-1221.

Hart, F., \& Bond, M., 1995. Action research for health and social care: a guide to practice: McGraw-Hill Education (UK). 
Homer, C., Brodie, P., Sandall, J., \& Leap, N., 2019. Midwifery continuity of care: Elsevier, Australia.

Information Commission Office, 2018. Accessed from:

https://www.gov.uk/government/publications/guide-to-the-general-data-protection-regulation

Kleppel, L., Suplee, P., Stuebe, A., Bingham, D., 2016. National Initiatives to Improve Systems for Postpartum Care. Maternal \& Child Health Journal, 20, 66-70.

Lewis, M., Jones, A., \& Hunter, B., 2017. Women's experience of trust within the midwifemother relationship. International Journal of Childbirth, 7(1), 40-52.

Marchant, S. and Garcia, J., 2000. The need to talk after birth: evaluating new services. In: J. Alexander, J., Roth, C. and Levy, V. (Eds), Midwifery Practice: Core Topics 3. Palgrave, London, pp.19-28.

National Health Service (NHS), 2016. National Maternity Review: Better Births - improving outcomes of maternity services in England. A five year forward view of maternity care, NHS, England.

National Health Service Information Services Division, 2016. Births in Scottish Hospitals, National Health Service National Statistics, Information Services Division Scotland.

National Institute for Health and Care Excellence (NICE), 2006. Postnatal Care up to 8 weeks after Birth. NICE; 2015 [updated February 2015; cited 2018 November]. Available from: http://www.nice.org.uk/guidance/CG37.

Newburn, M. and Bhavnani, V., 2010. Left to your own devices: The postnatal care experiences of 1260 first-time mothers, National Childbirth Trust (NCT).

North-West London Sustainability and Transformation Plans (STP). 2018. Personalised Postnatal Care Plan, Evaluation and Personal Care Plans for Mums and Families. England: North-West London Sustainability and Transformation Plans (STP).

Rogers, A. 2018. Transforming postnatal care. British Journal of Midwifery, 26(4), 216, Available from: https://doi.org/10.12968/bjom.2018.26.4.216.

Royal College of Midwives (RCM), 2000. Vision 2000, London: Royal College of Midwives.

Royal College of Midwives (RCM), 2014. Pressure Points Campaign - Postnatal Care Planning, London: Royal College of Midwives.

Royal College of Midwives (RCM), 2016. Why midwives leave - Revisited. RCM, London 
Rudman, A.,Waldenström, U., 2007. Critical views on postpartum care expressed by new mothers. BMC Health Services Research, 7, 178, https://doi.org/10.1186/1472-6963-7-178

Sandall, J., Soltani, H., Gates, S., Shennan, A., \& Devane, D., 2016. Midwife-led continuity models versus other models of care for childbearing women. Cochrane Database of Systematic Reviews, 4.

Scottish Government, 2017. The Best Start - a five-year forward plan for maternity and neonatal care in Scotland, Scottish Government, Scotland.

Scottish Government, 2015. Having a baby in Scotland, 2015. Listening to mothers, Scottish Government, Scotland.

Waldenström, U., Rudman, A., \& Hildingsson, I., 2006. Intrapartum and postpartum care in Sweden: Women's opinions and risk factors for not being satisfied. Scandinavica, Acta Obstetrica et Gynecologica, 85, 551-560.

Waterman, H., Tillen, D., Dickson, R., \& De Koning, K., 2001. Action research: a systematic review and guidance for assessment. Health technology assessment, 5(23), iii.

World Health Organization (WHO), 2014. WHO recommendations on postnatal care of the mother and newborn, Geneva, Switzerland.

Zadoroznyj, M., Brodribb, W.E., Young, K., Kruske, S., Miller, Y.D., 2015. 'I really needed help': What mothers say about their post-birth care in Queensland, Australia. Women \& Birth. 28(3), 246-251. 